\title{
Design and Implementation of HMI-based Integrated Energy Usage-Monitoring System
}

\author{
Jong-Chan Kim ${ }^{1}$, Se-Hoon Jung ${ }^{2}$, Kim Cheeyong ${ }^{3}$ and Eung-Kon Kim ${ }^{1 *}$ \\ ${ }^{1}$ Dept. of Computer Engineering, Sunchon National University \\ ${ }^{2}$ Dept. of Multimedia Engineering, Sunchon National University \\ ${ }^{3}$ College of ICT, Major of Game Animation Engineering, Doug-Eui University \\ ${ }^{1}$ seaghost@sunchon.ac.kr ${ }^{2}$ iam1710@hanmail.net, ${ }^{3}$ kimchee@deu.ac.kr. \\ ${ }^{1}$ kek@sunchon.ac.kr
}

\begin{abstract}
Electric power has a significant impact on the whole range of people's daily lives, as well as on industry, especially in the era of high oil prices. Furthermore, it becomes fundamental for encouraging the information society. Domestically, the integrated energy business contributes highly to rationalization of nationwide energy efficiency. Based on prior experience of using flue gas as an energy source in a combined heat and power (CHP) plant, the use of a variety of unused energy generated inside and outside of a power plant is being carried out.

This study aims at examining and implementing a system in which a PLC collects energy-related data at a CHP plant from meters, a human-machine interface (HMI) server acquires the data and stores them in a database $(D B)$ server, and a web application server conducts remote monitoring, calculates usage charges and generates bills. In an existing system, if an error or fault occurs in a meter or in communications equipment, usage amounts for the faulty duration must be calculated using an Excel spreadsheet, and those manually calculated data need to be updated in the DB by hand. To address these disadvantages, this paper proposes a mechanism of automatically extracting data related to faulty durations in the system, automatically calculating the usage amounts and excess amounts based on the values measured before and after the error occurred. Using the proposed system, energy efficiency is expected to improve. Additionally, it will be an optimized operational mechanism for managing integrated energy.
\end{abstract}

Keywords: Integrated Energy, Monitoring System, Combined Heat and Power (CHP) Plant, Human-Machine Interface (HMI)

\section{Introduction}

In the era of high oil prices, countries around the world put many efforts into improving efficiency at power generation plants. Also they seek ways to maximize efficiency in the generation and distribution of power while concerning themselves with high quality, low prices, and stability. At present, electric power has a significant impact on the entire range of people's daily lives, as well as industry, and it is also becoming a driving source to encourage the information society. In Korea, a competition principle has been introduced into the electricity industry. As demand for power consumption sharply increases, a lot of attention is being paid to rationalization of energy use $[1,2,7]$.

When generating electricity using a fossil fuel like coal, only one-third of the heat is converted to electricity, and the rest is unused and wasted. As such, a type of power generation that reuses the wasted heat for buildings and households in the local region is 
called combined heat and power (CHP) generation. Using this type of power generation, a power plant that generates power and sells both heat and electricity is called a CHP plant.

Some CHP plants also perform waste incineration at the same time. For example, the Mokdong CHP plant collects all waste from around the region and incinerates it at $700^{\circ} \mathrm{C}$ or higher to avoid the emission of toxic materials, like dioxin, that could come out due to incomplete combustion. It can improve landfill efficiency, because the combusted ashes occupy quite a smaller volume than before incineration. Electricity and hot water generated by waste incineration are supplied to the local area so that apartments and public facilities in adjacent areas can use hot water at a lower price $[3,4,8]$.

A CHP plant generates steam and conveys that steam to households through pipelines. An individual household makes a contract in advance for the amount per hour that is going to be used. If they use more than the agreed amount, they are charged for the excess amount at twice the contracted rate. A meter is installed on each pipeline connecting to a household. The required functionalities are as follows: the data read from the meter need to be sent to the billing system via human-machine interface (HMI) system; the amount of steam used by each household needs to be monitored and recorded for different times, based on a time-of-use tariff; and the household's bill needs to be calculated and issued.

In an existing system, if data have not been entered into the system properly because of an error or a fault occurring in the meter or communications link, usage amounts for the faulty duration need to be calculated by hand using a spreadsheet, and those manually calculated data need to be updated in the database (DB) by hand. It means that the correction of erroneous situations must be automated. If automation is accomplished, usage calculations can be more accurate, with less time taken and effort made. Additionally, an excess-usage fee could be charged, even for faulty durations.

To address these disadvantages, this paper proposes to implement an HMI-based CHP plant usage-monitoring and billing system focusing on functionalities to automatically detect faulty durations in the system, and to calculate usage amounts and excess amounts for the faulty duration, making use of values automatically read before and after the fault occurred.

\section{Combined Heat and Power plant}

\subsection{Efficiencies of CHP generation and systems}

The efficiency of CHP generation is calculated as a ratio of input to output. The efficiency of power generation assumes that the CHP system is a power generator, which is important, since fundamental efficiency indicates performance. Heat recovery efficiency is considering the CHP system to be heat generation equipment, indicating the performance of exhaust heat recovery. Overall efficiency is an estimation of both power and heat generated by the CHP system. Usage efficiency indicates the efficiency of power and/or heat generated by the CHP system in terms of the overall system, including generation facilities or buildings served $[2,5,6]$.

Electricity demand and heat demand for a building are denoted as A in kilowatt hours $(\mathrm{kW} / \mathrm{h})$ and $\mathrm{B}$ in kilocalories per hour $(\mathrm{kcal} / \mathrm{h})$, respectively. Considering a commercial power supply and a boiler arrangement for an existing system, calorie-based energy consumption $\mathrm{Q}_{1} \mathrm{~A}(\mathrm{kcal} / \mathrm{h})$ can be written as follows:

$$
\mathrm{Q}_{1 \mathrm{~A}}=\frac{\mathrm{A} \times 860}{\eta \mathrm{T}}
$$

$\eta_{\mathrm{T}}$ : Heat efficiency of thermal power generation

And energy consumption for heat demand, ${ }^{\mathrm{Q}_{\mathrm{B}}}(\mathrm{kcal} / \mathrm{h})$, can be expressed as follows:

$$
\mathrm{Q}_{1 \mathrm{~B}}=\frac{\mathrm{B}}{\eta_{\mathrm{B}}}
$$


$\eta_{\mathrm{T}}$ : Heat efficiency of thermal power generation

Therefore, calorie-based energy consumption in a traditional system, ${ }^{Q_{1}}(\mathrm{kcal} / \mathrm{h})$, can be expressed as follows:

$$
\mathrm{Q}_{1}=\mathrm{Q}_{1 \mathrm{~A}}+\mathrm{Q}_{1 \mathrm{~B}}=\frac{\mathrm{A} \times 860}{\eta_{\mathrm{T}}}+\frac{\mathrm{B}}{\eta_{\mathrm{B}}}
$$

Next, consider a CHP generation system that operates corresponding to the electric power demand. Calorie-based energy consumption for electric power demand, $Q_{2 A}$ ( $\mathrm{kcal} / \mathrm{h})$, can be expressed as follows:

$$
\mathrm{Q}_{2 \mathrm{~A}}=\frac{\mathrm{A} \times 860 \times(1-\mathrm{k})}{\eta_{\mathrm{T}}}+\frac{\mathrm{A} \times 860 \times \mathrm{k}}{\eta_{\mathrm{p}}}
$$

where $\mathrm{k}$ is the proportion of self-power generation over electric power demand $(0 \leq \mathrm{k} \leq 1)$ and $\eta_{\rho}$ is self-power generation efficiency.

Calorie-based energy consumption for heat demand, ${ }^{Q_{2 B}}(\mathrm{kcal} / \mathrm{h})$, can be written as follows:

$$
\mathrm{Q}_{2 \mathrm{~B}}=\mathrm{B}-\frac{\mathrm{A} \times 860 \times(1-\mathrm{k})}{\frac{\eta_{\mathrm{p}}}{\eta_{\mathrm{p}}}} \times\left(\eta_{\mathrm{c}}-\eta_{\mathrm{p}}\right)
$$

where ${ }^{\eta_{\mathrm{c}}}$ is total efficiency of the prime mover of the CHP system.

$\mathrm{Q}_{2 \mathrm{~B}}=0$ if $\mathrm{Q}_{2 \mathrm{~B}}<0$.

Therefore, calorie-based energy consumption of a CHP generation system, ${ }^{Q_{2}}(\mathrm{kcal} / \mathrm{h})$, can be expressed as follows.

$$
\begin{aligned}
& \text { When } \mathrm{Q}_{2 \mathrm{~B}}<0, \\
& \qquad \begin{array}{l}
\mathrm{Q}_{2}=\mathrm{Q}_{2 \mathrm{~A}_{+}} \mathrm{Q}_{2 \mathrm{~B}}=\mathrm{A} \times 860 \mathrm{X}\left(\frac{1-\mathrm{k}}{\eta_{\mathrm{T}}}+\frac{\mathrm{k}}{\eta_{\mathrm{p}}}-\frac{\mathrm{k}\left(\eta_{\mathrm{c}}-\eta_{\mathrm{p}}\right)}{\eta_{\mathrm{B}} \times \eta_{\mathrm{p}}}\right)+\frac{\mathrm{B}}{\eta_{\mathrm{B}}} \\
\text { When } \mathrm{Q}_{2 \mathrm{~B}} \leq 0, \\
\mathrm{Q}_{2}=\mathrm{A} \times 860 \mathrm{X}\left(\frac{1-\mathrm{k}}{\eta_{\mathrm{T}}}+\frac{\mathrm{k}}{\eta_{\mathrm{p}}}\right)
\end{array}
\end{aligned}
$$

Using equation 7, the energy savings rate, $\mathrm{S}(\%)$, can be estimated as follows. The energy savings rate can be estimated using a general value for each efficiency: ${ }^{\eta_{\mathrm{T}}}=0.35$, $\eta_{\mathrm{B}}=0.9, \eta_{\mathrm{P}}=0.75, \eta_{T}=0.30$, and $\eta_{\mathrm{P}}=0.20$

The purpose of CHP generation is to realize economical energy management by producing heat and electricity at the same time. It is a total energy system that can simultaneously generate two different types of energy (heat and electricity) using the same fuel. Generally, CHP generation operates in two parts. The high temperature part is used as moving power, whereas the low temperature part is used as heat $[2,7,8]$.

A cogeneration system is a total energy system that simultaneously generates electric power and heat from one energy source. Since this system recycles and reuses exhaust heat generated along with the power generation process, and can improve heat usage efficiency in terms of total energy, lots of attention is being paid to such systems as a source of energy or heat for industrial facilities and residential buildings.

A CHP generation system is highly efficient energy usage technology, achieving a 30$40 \%$ energy savings effect compared to the traditional ways of power generation, because it recovers and reuses exhaust heat released in the primary power generating process by means of a self-power-generating facility without relying on power distributed by an external power supply company and uses the electricity and heat energy for operating boilers in industrial facilities and buildings. Recently, thermal power plants have shown $40 \%$ power generation efficiency. Considering losses occurring during transmission, usage efficiency is considered to be approximately $35 \%$. Cogeneration systems can be 
divided into various types according to constituent equipment, the corresponding load, and the method of operation. Figure 1 shows an overview of a cogeneration system.

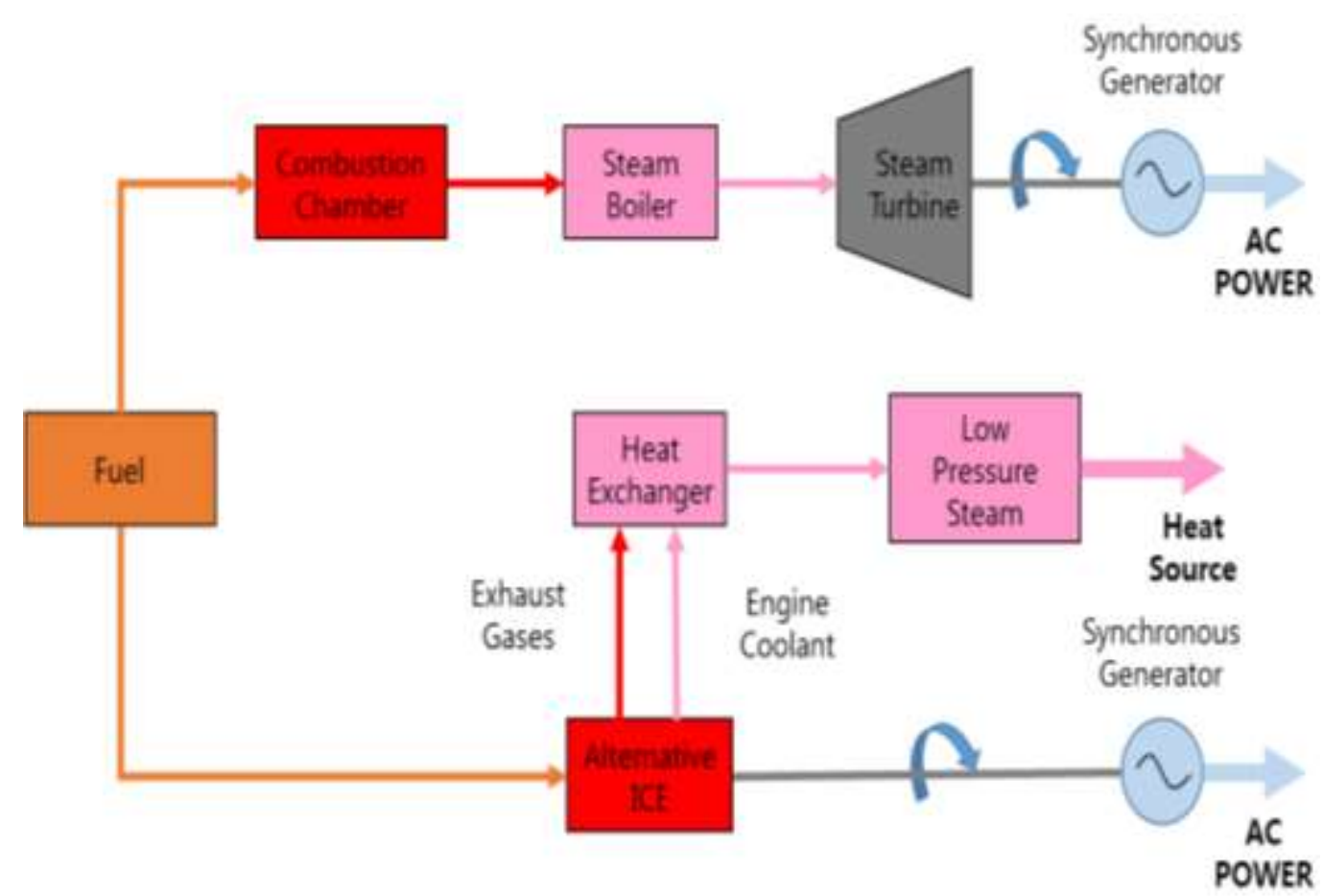

Figure 1. Overview of a CHP Generation System

\subsection{Advantages and Disadvantages of CHP Systems}

CHP generation in its broad meaning is defined as a system that uses primary energy and subsequently generates two or more different types of secondary energies. In fact, it is a system that runs a prime mover, such as a gas engine, diesel engine, or gas turbine, using liquid petrol gas (LPG), natural gas, or oil, and can effectively utilize the moving power and exhaust heat. This system has an advantage in that it can generate electric power and heat energy simultaneously, and overall energy efficiency is enhanced (total energy efficiency: $75-90 \%$ ) by making effective use of exhaust heat as well. Since it is based on distributed resources, it can be used for the purposes of peak-cut in the summer season, contributes to a stable power supply, and reduces relevant costs, including installation costs and losses due to long-distance power transmission. Self-power generation could contribute to lowered electric bills and even earn money by selling the self-generated power to the electricity company. One of the measurements undertaken to maintain a stable electric power supply is to allow private corporations to participate in CHP generation projects, which leads to a reduction in the additional facilities required by electric power companies. Use of clean fuel like LPG contributes to carbon dioxide suppression, and reduces the environmental pollution problem.

There are also disadvantages. Relatively large amounts of money are required for investment. Unit facilities are significantly small, compared to an existing power generation facility of a traditional power company. Potential risks exist due to uncertainty in future fuel prices and diseconomies of scale because fossil fuels (gas and oil) are mainly used. It is potentially possible that benefits coming from energy usage efficiency might exceed the return on investment in cases where the proportion of heat and electric power demand is not appropriate, or where uncertainty about demand fluctuations is high. 


\section{Design and Implementation of an HMI-based Integrated Energy Usage-Monitoring System}

An HMI-based integrated energy usage-monitoring system is one in which CHP plant energy-related meter data are acquired by HMI servers from a PLC and stored in a DB server, and where remote monitoring through a WAS and billing are carried out.

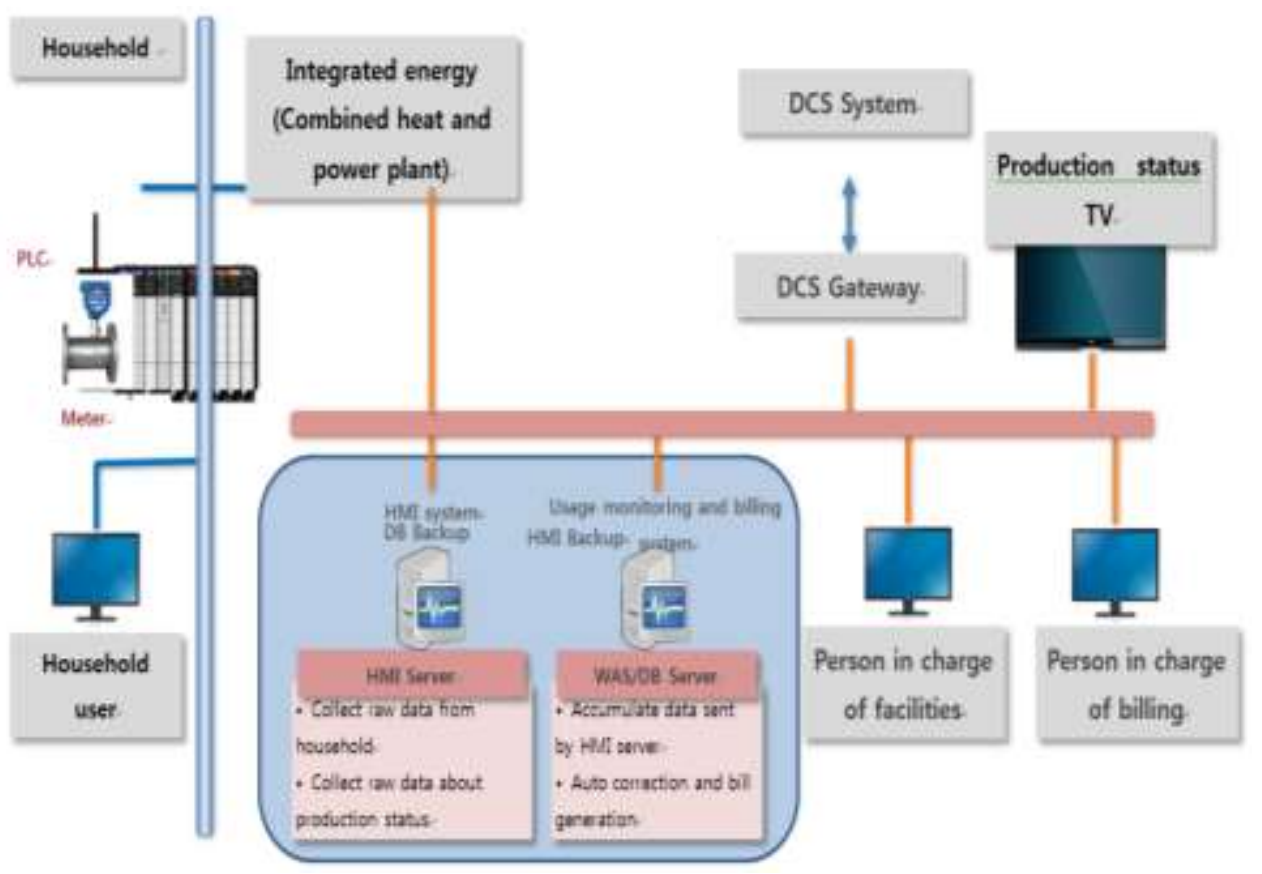

Figure 2. Architecture of the HMI-based Integrated Energy UsageMonitoring System

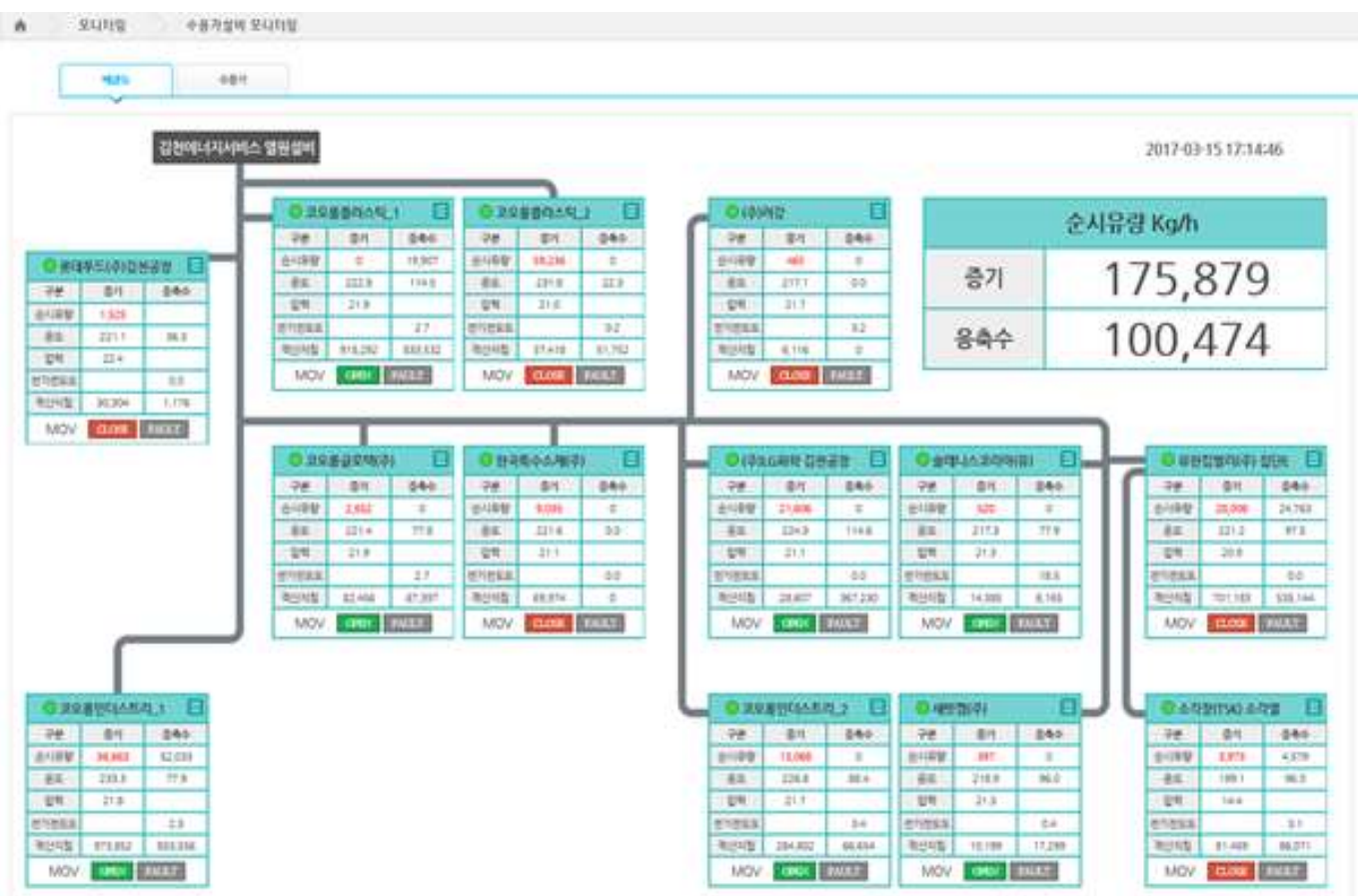

Figure 3. Screen Shot Showing Usage-Amount Monitoring 
A CHP plant generates steam and supplies steam to each household through a pipeline. To support this, functionalities monitor how much steam is used by each household, accumulate usage amounts at different times, and issue bills. The system implementation environment is as follows: Apache 2.0.62 was used for the Web server, Tomcat 8.5.0 was used for the WAS, and ORACLE 11g, JDK 8.0.12.10 is the DB server. Figure 2 shows the system architecture of the HMI-based integrated energy usage-monitoring system.
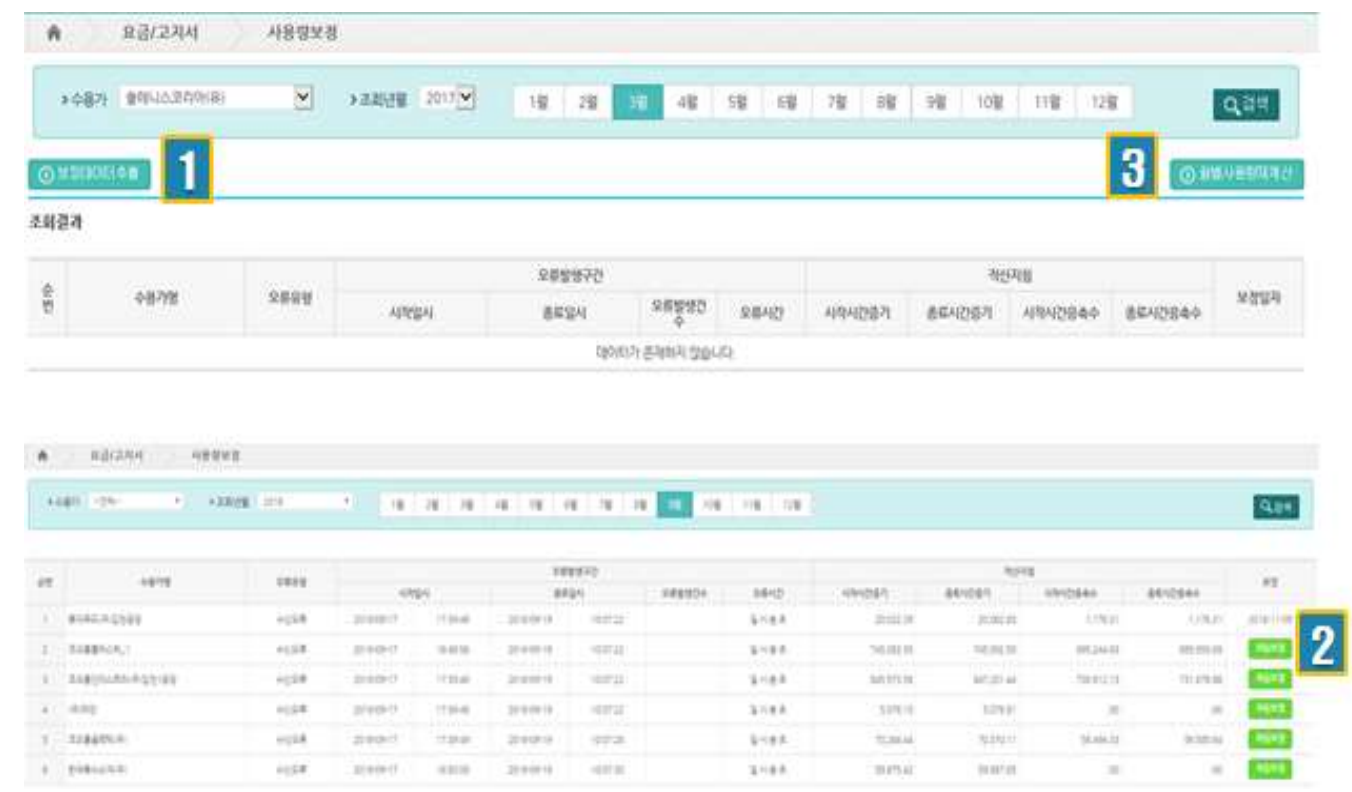

Figure 4. Extracting Targets Necessary To Correct and Automatic Correction of Them

In this paper, four functionalities were implemented: real-time usage amount monitoring, automatic correction of usage amounts, reporting, and billing. Real-time usage-amount monitoring allows people to monitor usage amounts in each household and the recovered condensate water amounts on a real-time basis. A usage-amount automaticcorrection function carries out automatic correction of usage by identifying faulty durations when usage amounts of steam cannot be calculated due to a communications link error with the meter. When a correction is done by hand, excessive usage amounts cannot be calculated. Automatic correction is capable of doing this as well. A reporting function allows users to generate and print various types of reports, such as reports with data sorted by time, day, month, and year. Downloading data in the form of an Excel spreadsheet is also supportable. The billing function allows staff to calculate monthly usage charges based on the agreed contract price and tariffs, and to generate and edit bills. 


\begin{tabular}{|c|c|c|c|c|c|c|c|c|c|c|c|c|c|}
\hline A & 포건 & 파늘서 & & & & & & & & & & & \\
\hline sebs & 2newaras: & सद्या & matro & arnevis o & 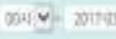 & ts lowe & & & & & & & Q974 \\
\hline Qhass & & & & & & & & & & & yosn. & gestate & 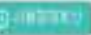 \\
\hline \multirow{3}{*}{$5 x$} & \multirow{3}{*}{ Net } & \multicolumn{6}{|c|}{ fruge } & \multicolumn{6}{|c|}{ Agert } \\
\hline & & \multicolumn{3}{|c|}{ \$NAs? } & \multirow{2}{*}{ aceant } & \multirow{2}{*}{ ร724มี } & \multirow{2}{*}{ aptespols } & \multicolumn{3}{|c|}{ करxisate } & \multirow{2}{*}{ Awant } & \multirow{2}{*}{ 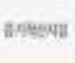 } & \multirow{2}{*}{ 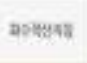 } \\
\hline & & syar & कात & sayer & & & & AUEII & 495 & Laut: & & & \\
\hline 2arters & ㅍ-EN & 3595 & 3596 & in & na & mast & Hiss & & & & & & ค \\
\hline 201\%?! & $\theta-\cos \theta$ & HAl & kett & 100 & $\operatorname{mis}$ & meant & ตอง & & & & & & \\
\hline चर्भis & ए-1040 & $\mathrm{sin}$ & ent & $t w$ & wese & 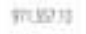 & 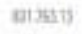 & & & & & & \\
\hline सात्राओ & se-041 & 313 & $x z$ & 150 & 46 is & काष्य & 35: & & & & & & \\
\hline xirats & 20.65e & अर्ब & $x+3$ & $6 x$ & He & 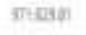 & Disas & & & & & & \\
\hline 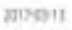 & D5. 004 & we & wa & 100 & 174 & тинан & stand & & & & & & \\
\hline mingit & $0-204$ & S65T & 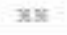 & 150 & ste & moraco & aisis & & & & & & \\
\hline साओस्य & Ex-tail & His & 20.5 & $\$ x$ & 148 & milate & 314940 & & & & & & \\
\hline zisest & ab. 0 ovi & nas & xin & ino & $m=$ & muss & piwsm & & & & & & \\
\hline याभक्णा। & {$[F-181$} & Has & 30 & 10 & 猉䄈 & 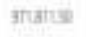 & ateosit. & & & & & & \\
\hline Х1НМ3 & 15. 184 & 3398 & 383 & 100 & $=106$ & 9T: s:3:3 & C015\% & & & & & & \\
\hline 2інан & $f 1=124$ & mali & $x+1$ & 10 & 326 & Itrusis & moen & & & & & & \\
\hline
\end{tabular}

Figure 5. Download of a Manual Calibration Target as an Excel File

Figure 3 shows the screen in which staff can monitor steam usage amounts for all households on a real-time basis. Figure 4 is a screen showing a data error happening because of a communications error, a PLC error, or malfunctioning meter. Figure 5 shows a manual calibration target as an Excel file and reflects the correction. Figure 6 shows the creation of an itemized notice and an e-mail address. In this case, the system automatically detects the duration when a correction is necessary, and rectifies the usage amount, referring to data recorded before and after occurrence of the error or fault. Table 1 shows the algorithm used for correcting the erroneous target.

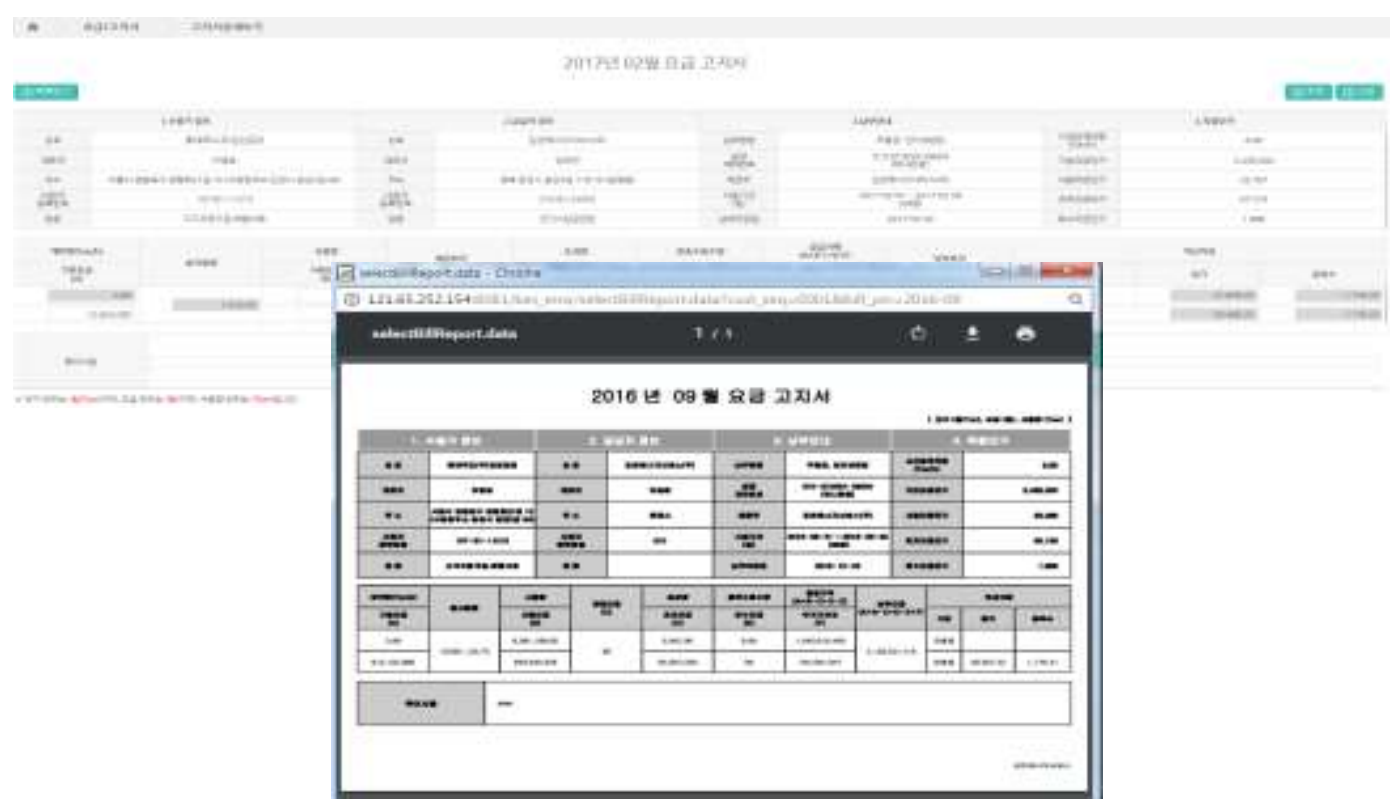

Figure 6. Generate and E-Mail a Perceptual-Specific Bill 


\section{Table 1. Algorithm for Automatically Detecting Target Necessary to Correct}

Categorize errors into three types to detect target to be corrected.

1. Communications error: duration during which accumulated meter value remains the same for 10 minutes or longer

2. PLC error: duration during which accumulated meter value is 0

3. Receive error: duration during which no accumulated meter value is entered

To identify communications error-type duration automatically, you need to group values having the same accumulated meter value (steam_ci).

ROW_NUMBER() over (PARTITION BY cust_seq, steam_ci ORDER BY use_date, use_time) rn2

You need to fetch values before and after errors occurring in different durations.

LAG(steam_ci) OVER (ORDER BY cust_seq, use_date, use_time) AS before_steam_ci LEAD(steam_ci) OVER (ORDER BY cust_seq, use_date, use_time) AS after_steam_ci

The functionalities that this system has focused on are automated extractions of faulty durations from the system, and automated calculations of usage amounts and excessive amounts for faulty durations based on values measured before and after the faults. Through automation of those functions, accurate usage calculations, time savings, and charges for excessive amounts for faulty durations can be achieved.

\section{Conclusion}

This paper aims at implementing an HMI-based, integrated energy usage-monitoring system to enable real-time usage monitoring and to identify problems promptly. The proposed system contributes to the reduction of processing times and to accurate calculations of usage amounts for faulty time periods, which leads to an increase in convenience for management and improvement of work efficiency by means of diverse analysis. In an existing system, if data have not been entered into the system because of an error or fault occurring in a meter or communications link, usage amounts for the faulty durations are calculated using an Excel spreadsheet, and those manually calculated data need to be updated in the DB by hand. The proposed system is expected to enable calculations of excessive usage amounts for faulty durations using an automated correction function and to improve energy efficiency, and it will be an optimized operational mechanism for integrated energy in the long run.

Future work will address two limitations in the proposed system. If a fault occurs at the end of the month and remains unchanged until the following month, the accumulated meter value after the error occurred cannot be known until the bill comes out the following month. Another limitation is the case of a meter that malfunctions. While the meter is faulty, usage amounts cannot be known, but the proposed system has no function to handle this situation. Therefore, further study will be necessary to add those functions.

\section{References}

[1] S. H. Min, H. Y. Choi and S. H. Yoo, "Estimation of the Benefits from Integrated Energy-based CHP's Reducing Thermal Discharge: A Comparison with Coal-fired Generation", Journal of Energy Engineering, vol.24, no. 4, (2015), pp.223-231.

[2] K. T. Han, H. M, Kim and S. H. Yoo, "The Economic Effects of Integrated-Energy Business: An InputOutput Analysis", Journal of Energy Engineering, vol.21, no. 1, (2012), pp. 4754.

[3] S. Y. Lim, S. Y. Park and S. H. Yoo, "The Economic Effects of the New and Renewable Energies Sector", Journal of Energy Engineering, vol.23, no. 4, (2014), pp.31-40,. 
[4] I. K. Choi, I.Y. Jeong, and M.S. Shin, "A Review on the Control System of Heat Recovery Steam Generator for Large Scale Combined Cycle Powr Plant," KIEE Summer Conference, (2011), pp. 18121813.

[5] T. K. Kim, S. D. Oh, Y. H. Kwon, S. H. Seo and B. Y. Kim, "Development of a Thermal Design Software for the Heat Recovery Steam Generator of Combined Cogeneration System", KSME, (2001), pp. 726-731.

[6] H. J. Kim, H. Y. Choi and S. H. Yoo, "Measuring the benefits from integrated energy business-based combined heat and power plant as a decentralized generation source with a focus on avoiding the damages caused by large-scale transmission facilities", Journal of Energy Engineering, vol.24, no. 3, (2015), pp. 67-73.

[7] S. Y. Park, H. H. Shin and S. H. Yoo, "Economic Feasibility Analysis of Building Seonam Biogas Combined Heat and Power Plant", Journal of Energy Engineering, vol.25, no. 4, (2016), pp. 141-151.

[8] H. Y. Choi, M. H. Ryu and S. H. Yoo, "Public Preferences for Replacing Hydro-Electricity Generation with Coal-Fired Power Generation,” Journal of Energy Engineering, vol.24, no. 1, (2015), pp. 164-171.

\section{Authors}
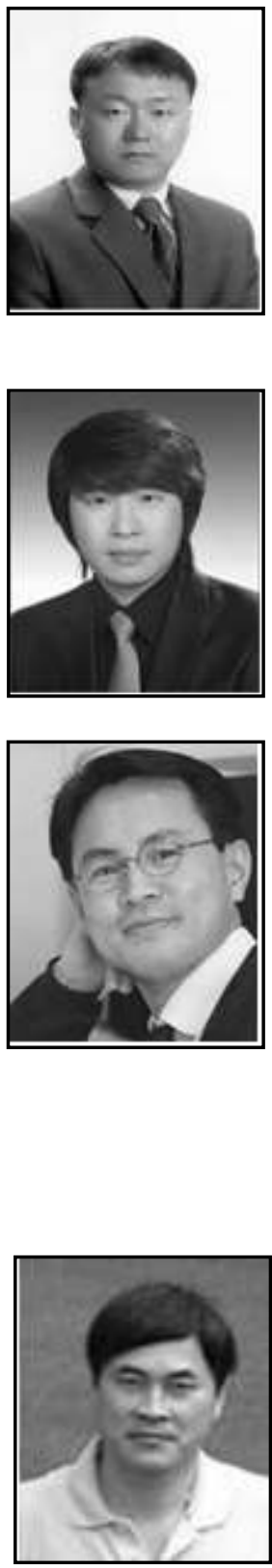

Jong-Chan Kim, he received his BSc from Sunchon National University in 2000, his MSc from the Department of Computer Science, Sunchon National University, in 2002, and his PhD from the Department of Computer Science, Sunchon National University, in 2007. He has been a senior research professor in the Automation and System Research Institute at Seoul National University since 2013. His current research interests are image processing, computer graphics, digital clothing, AR, and games.

Se-Hoon Jung, he received his BSc and MSc in Multimedia Engineering from Sunchon National University in 2010 and 2012, respectively. Currently, he is a team manager with the research \& development team, Gwangyang Bay SW Convergence Institute, South Korea. His research interests include data analysis and data prediction.

Kim Cheeyong, he received a BSc, an MSc and a PhD from Inje University, Republic of Korea in 1991, 1994, and 2000, respectively. He was a visiting professor at Oxford University in 2007, and a visiting professor in the Digital Clothing Center at Seoul National University in 2012. Currently, he is a professor in the College of ICT, Major of Visual Game Engineering, at Dong-Eui University. Prof. Kim held private exhibitions four times, in both Seoul and China, and has participated in more than 230 international group exhibitions. He has keen interests in 3D animation, fractal \& chaos design, computational simulations, game character design, and 3D virtual fashion fitting systems.

Eung-Kon Kim, he received a BSc from Chosun University, Gwangju,, Korea, in 1980. His MSc was from the Department of Electronics at Hanyang University in Seoul, Korea, in 1987. His PhD was from Chosun University in Gwangju, Korea, in 1992. His current research interests are computer vision, virtual/augmented reality, image processing, and computer graphics. Currently, he is a professor in the Department of Computer Engineering, Sunchon National University, Korea. 
International Journal of Control and Automation

Vol. 10, No. 10 (2017) 